\title{
Optical and Network Performance Analysis of XGS-PON System over Active Co-Existence PON Systems
}

\author{
D. Tarsono, A. Ahmad, K. Khairi, K. A. Sharif, M. H. Othman, N. A. Ngah, Z. A. Manaf \\ Communication Technology, TM Research \& Development, Cyberjaya, Malaysia \\ Email: dedy@tmrnd.com.my
}

How to cite this paper: Tarsono, D., Ahmad, A., Khairi, K., Sharif, K.A., Othman, M.H., Ngah, N.A. and Manaf, Z.A. (2017) Optical and Network Performance Analysis of XGS-PON System over Active Co-Existence PON Systems. Optics and Photonics Journal, 7, 40-48.

https://doi.org/10.4236/opj.2017.78B007

Received: April 30, 2017

Accepted: August 7, 2017

Published: August 10, 2017

\begin{abstract}
We proposed an enhanced Reach Extender (RE) called Active Co-existence (ACEX) and investigate its performance with respect to XGS-PON system that co-exist with GPON and TWDM-PON system. The RE is consists of hybrid optical amplifier integrated (EDFA and SOA) with Co-existence Element (CEX) module which is installed at the Central Office (CO) together with the OLT system and act as a booster and pre-amplifier for the downstream and upstream optical signal respectively. The results show that the proposed ACEX is capable to support XGS-PON operation for a maximum distance of $35 \mathrm{~km}$ with 128 splitting ratio and up to $44 \mathrm{~dB}$ link loss.
\end{abstract}

\section{Keywords}

GPON, XGS-PON, TWDM-PON, Co-Existence Element, Active Co-Existence, Reach Extender

\section{Introduction}

The IP traffic is expected to grow at Compound Annual Growth Rate (CAGR) of $22 \%$ from 2015 to 2020, rapidly driven by high bandwidth demand and high-end applications and services such as High-Definition Television (HDTV) which evolves towards $4 \mathrm{~K}-8 \mathrm{~K}$ resolution, Machine to Machine (M2M) communication and Internet of Everything (IoE) [1]. Due to the aggressive demand from the consumers and the need to expand the revenue by the network operators, the current optical access network should be upgraded by utilize co-existing PON technology with the Next Generation PON systems (NG-PON), capitalizing on the deployed optical distribution network (ODN) and optimizing the initial network investments. 
Current Gigabit PON (GPON) technology is widely deployed by many countries in the world covering the distance up to $20 \mathrm{~km}$ or less with 32 splitting ratio and loss budget of $28 \mathrm{~dB}$ using Class $\mathrm{B}+$ system [2]. XG-PON and 10 GEPON were then initiated to satisfy the increasing traffic demands with asymmetrical transmission (10 Gbps/2.5 Gbps) as speficied by ITU-T G.987 and IEEE standard 802.3. [3]. The Full Service Access Network (FSAN) community has proposed Time Wavelength Division Multiplexing-PON (TWDM-PON) as a future candidate for NG-PON $\mathrm{N}_{2}$ system by assigning several wavelengths for each OLT port with dynamic wavelength and bandwidth allocation (DWBA) for its communication flow control [4]. However the deployment of the TWDM-PON is temporarily halted by the high cost of the tunable optical transceivers. As a transition solution, 10 Gigabit Capable Symmetric Passive Optical Network (XGSPON) is introduced to deliver $10 \mathrm{Gbps}$ in both directions as well as supporting dual rate transmission [5]. The XGS-PON is complied with major requirements of NG-PON1 to co-existing with the current deployed G-PON system and utilizing its ODN that consumed $70 \%$ of the total investment in PON deployment [6].

The minimum requirement of XGS-PON is to support fiber distance of at least $20 \mathrm{~km}$ and 64 splitting ratio. In order to achieve longer reach, higher capacity, larger bandwidth and more users, ITU-T proposed the use of higher power transceivers and RE [7]. Previous work has proposed inline optical reach extender which able to operate in hybrid PON system with maximum distance of $30 \mathrm{~km}$ and link loss budget of $31 \mathrm{~dB}$ [7]. An optical amplifier based GPON reach extender deployed underground and demonstrated an error free operation over $28 \mathrm{~dB}$ on distribution loss [10]. Another option is using an Optical-ElectricalOptical (O-E-O) as an inline RE which is located $80 \mathrm{~km}$ from the OLT providing 128 splitting ratio with $59 \mathrm{~dB}$ link loss budget [8]. However, there is no electrical power source supplied to the current ODN, and inline RE approach will increase complexity and cost. Distributed Raman amplification will prevent such problem to arise [9] but the amplifier is not optimal for $1270 \mathrm{~nm}$ transmission and wide amplification spectrum could interfere, thus co-existence with other PON systems is not possible.

In this paper, we propose an enhanced reach extender called Active CEX (ACEX) that is installed together with the OLT systems at the CO. The performance of XGS-PON system co-existing with the current G-PON and TWDM-PON system in a single ODN setup is investigated. We characterize the gain and Noise Figure (NF) of the ACEX, and analyze the performance of the extended XGS-PON system in terms of frame loss and throughput for various values of distances and splitting ratios.

\section{Experimental Setup}

\subsection{ACEX Experimental Setup for PON Systems}

Figure 1 shows experimental configuration consists of co-existing G-PON, 


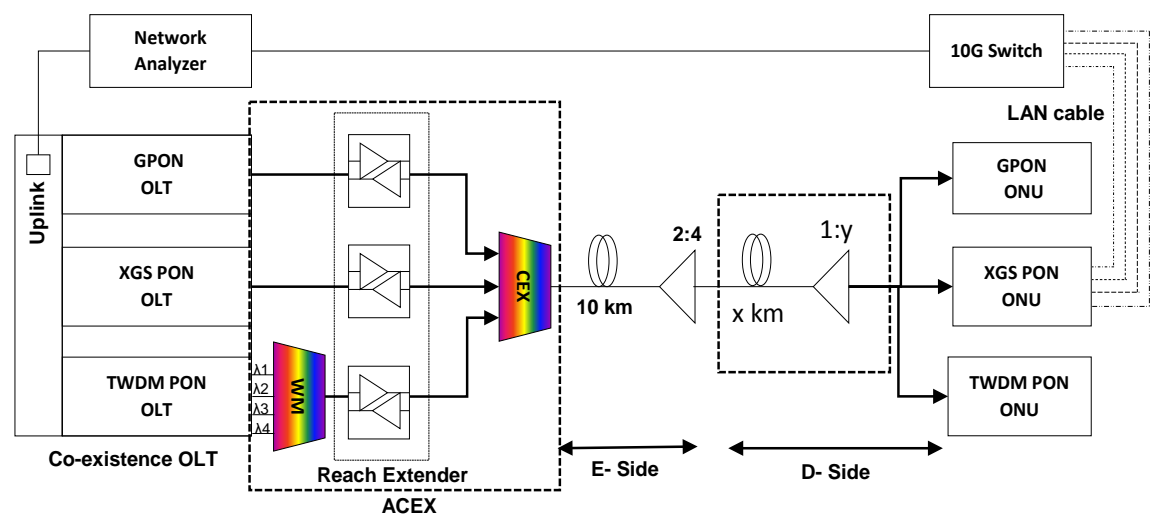

Figure 1. Experimental setup for coexistence system G-PON, XGS-PON and TWDMPON.

XGS-PON and TWDM-PON OLTs. The XGS-PON system utilizes $1577 \mathrm{~nm}$ and $1270 \mathrm{~nm}$ wavelengths for symmetrical $10 \mathrm{Gbps}$ downstream and upstream transmission respectively.

Complete wavelength plans of the co-exist PON systems as shown in Figure 2, depicts the legacy PON (G-PON) that XGS-PON and TWDM-PON systems must be considered relative to migration and co-existence requirements.

In order to realize co-existing system, passive CEX is installed to combine all the PON systems into the same fiber link. Meanwhile the TWDM-PON system needs a Wavelength Multiplexer (WM) to stack four pairs of wavelengths that would support aggregated rates of $40 \mathrm{Gbps}$ downstream and $10 \mathrm{Gbps}$ upstream [6]. Each PON systems are also equipped with RE to provide longer distance and higher splitting ratio. Specifically for XGS-PON, we have developed RE using Erbium Doped Fiber Amplifier (EDFA) for the downstream and Semiconductor Optical Amplifier (SOA) for the upstream transmission. All the passive CEX, WM and RE are integrated to form ACEX as shown in Figure 1.

We also prepared a testbed for the ODN that comprised of $10 \mathrm{~km}$ fiber cable for the Exchange side (E-side) with a $2 \times 4$ optical splitter (1st stage). We vary the Distribution side (D-side) fiber cable distance from 15 to $35 \mathrm{~km}$ and the second stage (2nd stage) optical splitter from $1 \times 4$ to $1 \times 32$ forming maximum splitting ratio of 128 .

The measurement are based on Ethernet frame loss and throughput analysis which is carried out using IXIA system on symmetrical $10 \mathrm{Gbps}$ bidirectional Ethernet traffic with frame length of 1518 bytes. The throughput measurement is limited by four RJ-45 ports for Gigabit Ethernet interfaces on the Optical Network Unit (ONU) output ports which provides maximum total throughput of 4 Gbps symmetrical.

\subsection{XGS PON Reach Extender}

For XGS PON, we have developed bidirectional reach extender to cater the downstream and the upstream optical signal using a pair of Multi Wavelength Di- 


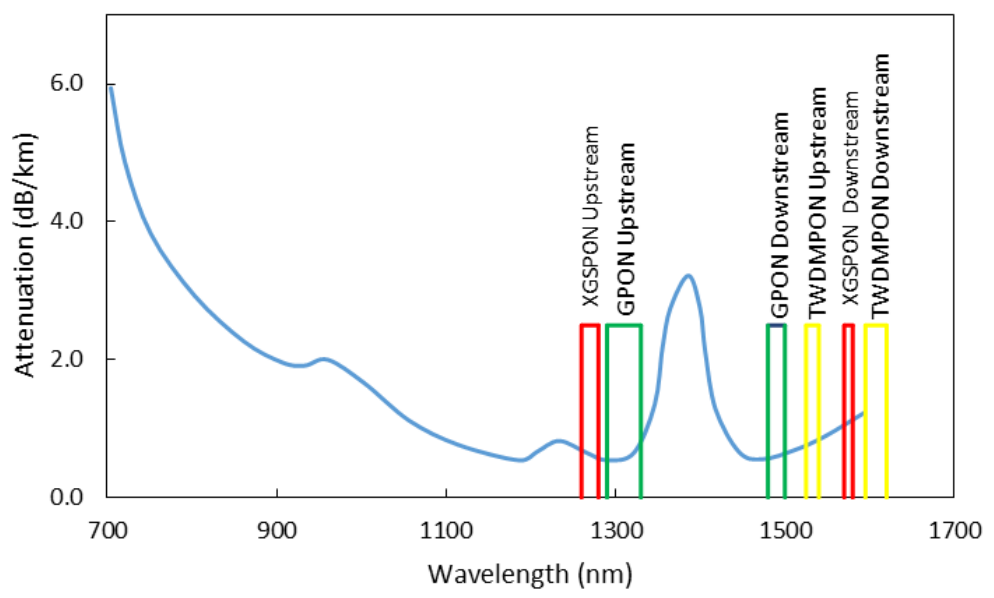

Figure 2. Complete wavelength plans across attenuation of G.652 single mode fiber (ITUT.G.652).

vision Multiplexers (MWDM) as shown in Figure 3. The downstream extender is consisted of Erbium Doped Fiber Amplifier (EDFA) which operates at $1577 \mathrm{~nm}$ and semiconductor amplifier (SOA) at $1270 \mathrm{~nm}$ for the upstream transmission. The reach extender is also equipped with monitoring and controller to ease monitoring and configuration of the extender. The reach extender is located with the OLT to simplify future maintenance and maintaining the passive optical access network.

\section{Result and Discussion}

In this section, the results are presented into two parts. The first part is the optical performance of XGS-PON Reach Extender and the second is network performance of XGS-PON coexist with PON systems.

\subsection{Optical Performance of XGS-PON Reach Extender}

Figure 4 shows the optical performance in terms of Output Power (Po), Gain and Noise Figure (NF) as a function of several values of Input Power (Pin) of the incoming wavelengths, $1577 \mathrm{~nm}$ and $1270 \mathrm{~nm}$ for downstream and upstream respectively.

For downstream performance, it can be seen an amplified of incoming signal where the output power for all pump laser diode (LD) current setting was achieved. By taking the incoming input power is $0 \mathrm{dBm}$ as a reference, it can be seen the output power was achieved up to $10 \mathrm{dBm}$ with $10 \mathrm{~dB}$ gain and the $\mathrm{NF}$ at $8.2 \mathrm{~dB}$. These values are adequate in order the signal transmitting over $\mathrm{dB}$ link loss to the receiving end (ONU).

The input power for upstream was set from $-16 \mathrm{dBm}$ to $-40 \mathrm{dBm}$ for all performance parameters (Po, Gain and NF) as the ACEX was placed at CO. These was an expected value range of input power from upstream (ONU) to OLT through ODN and it is also depends on the design of the network. From the results, the performance of output power and gain showed $-20 \mathrm{dBm}$ and $10 \mathrm{~dB}$, 


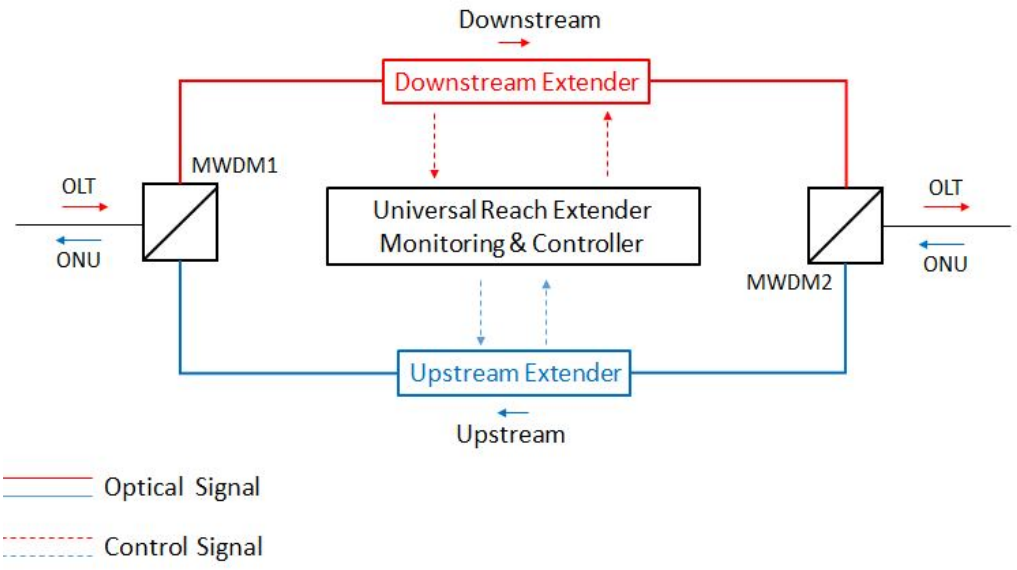

Figure 3. XGS-PON reach extender configuration.
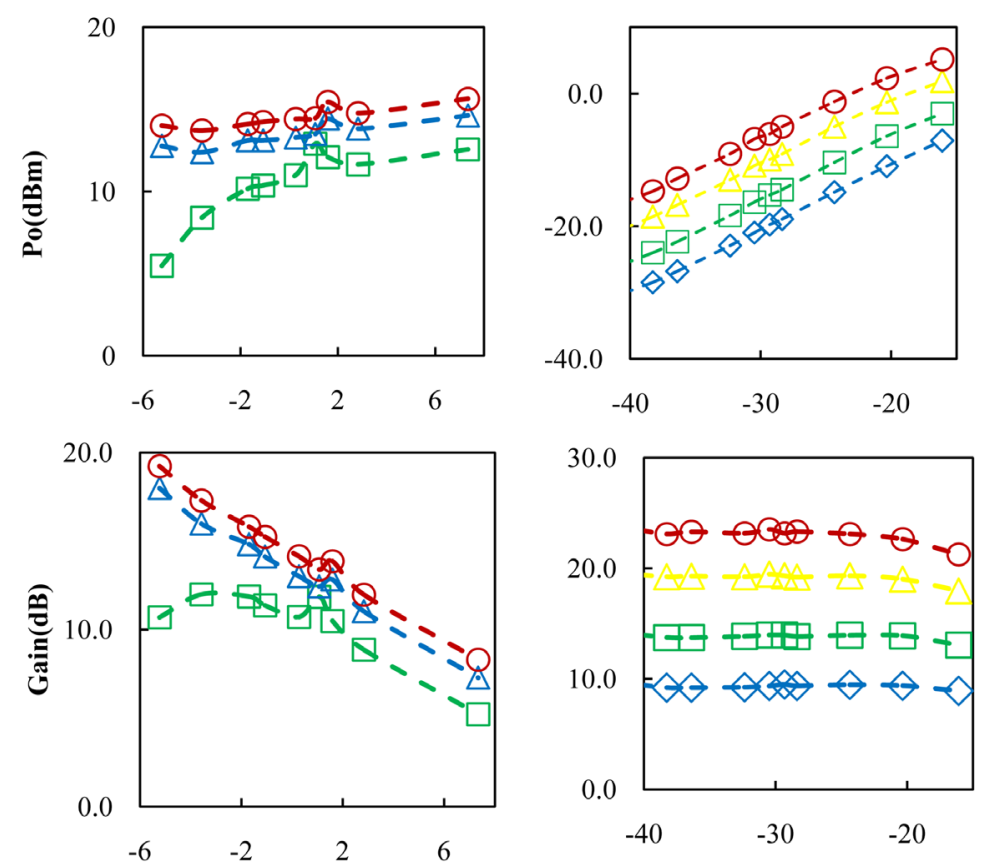

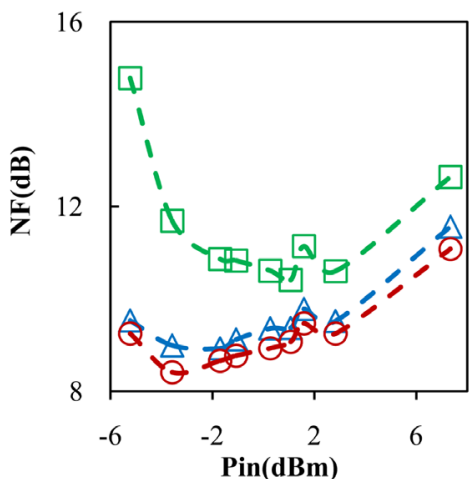
$-\square--180 \mathrm{~mA}$
$--\infty-280 \mathrm{~mA}$

$--\triangle--240 \mathrm{~mA}$

(a)

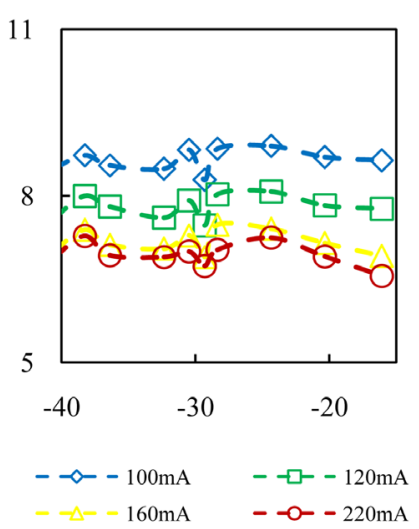

(b)

Figure 4. Optical performance (a) Downstream and (b) Upstream of ACEX. 
respectively. It can be noticed that the gain and NF are consistent for all values of incoming upstream signal. This is due to the fact that the upstream SOA was operating in a saturation region. For this design, the NF performance achieved between $7 \mathrm{~dB}$ to $9 \mathrm{~dB}$.

Figure 5 shows the measurement of loss of ODN for all network design. The results shows the loss of ODN propotional to the number of splitting ratio and distance. This is due to the fact that the difference value of insertion loss contributed from splitters as well as fiber distance. In our network design, the loss contributed from ODN which was consists of CEX, severals splitters, a distance of fiber and other passive components (connectors and adapters).

\subsection{Network Performance of XGS-PON Reach Extender}

The system performance of coexistence PON system network with ACEX is then evaluated in throughput for both downstream and upstream. Figure 6 shows the downstream throughput as a function of splitting ratio with several distance of fiber. The splitting ratio was effected at second stage splitter (D-side) as shown in Figure 1. The through put performance achieved 900Mbps for all type of splitting $(1: 16,1: 32,1: 64$ and 1:128) with respective distances. It can be seen that the network throughput was affected by the distance and splitting ratio as these parameters contributed to loss in the network. In order to maintain an optimum value of network throughput, the maximum splitting ratio is 1:128 with the distance of $15 \mathrm{~km}$, or up to $36.5 \mathrm{~dB}$ link loss.

The upstream throughput performance is depicted in Figure 7. The maximum throughput was achieved at $900 \mathrm{Mbps}$ and the minimum value is 876

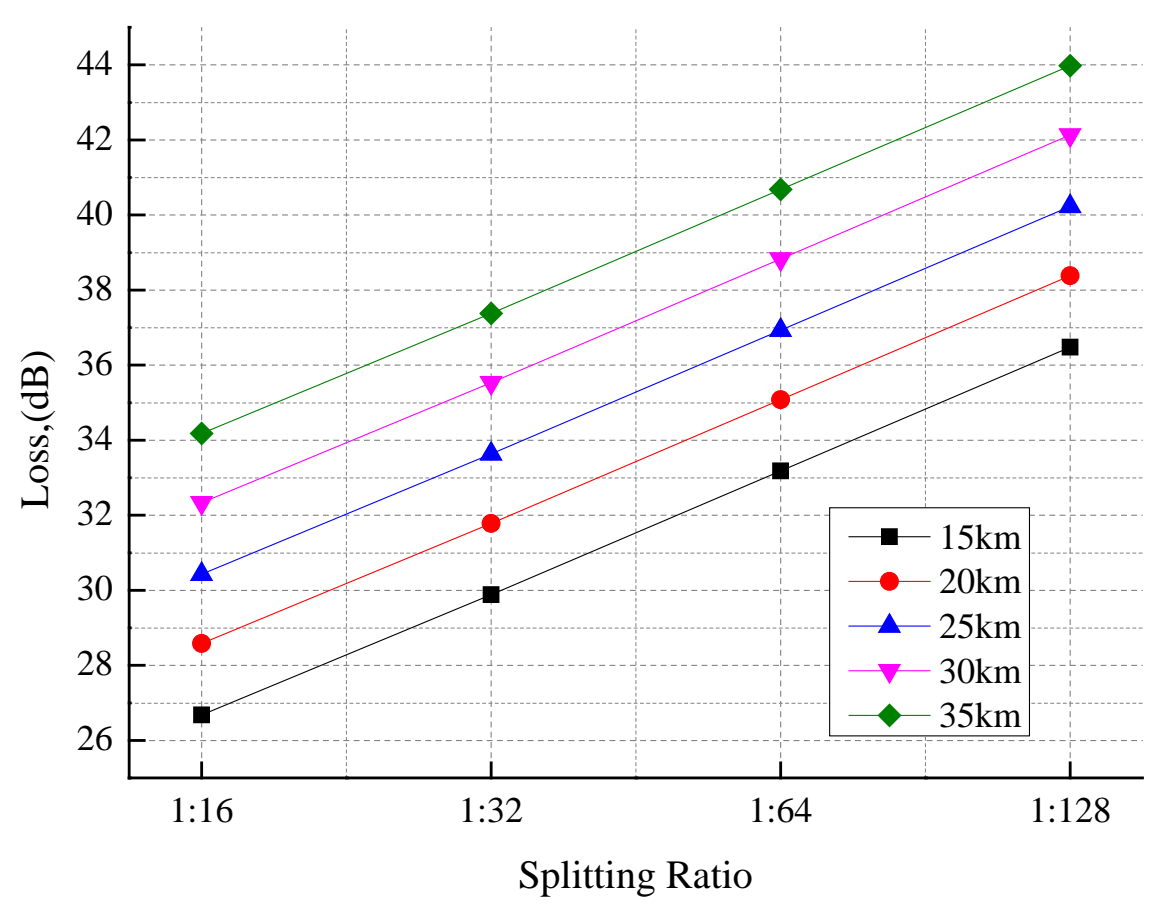

Figure 5. Link Loss of ODN to the number of splitting ratio and distance. 


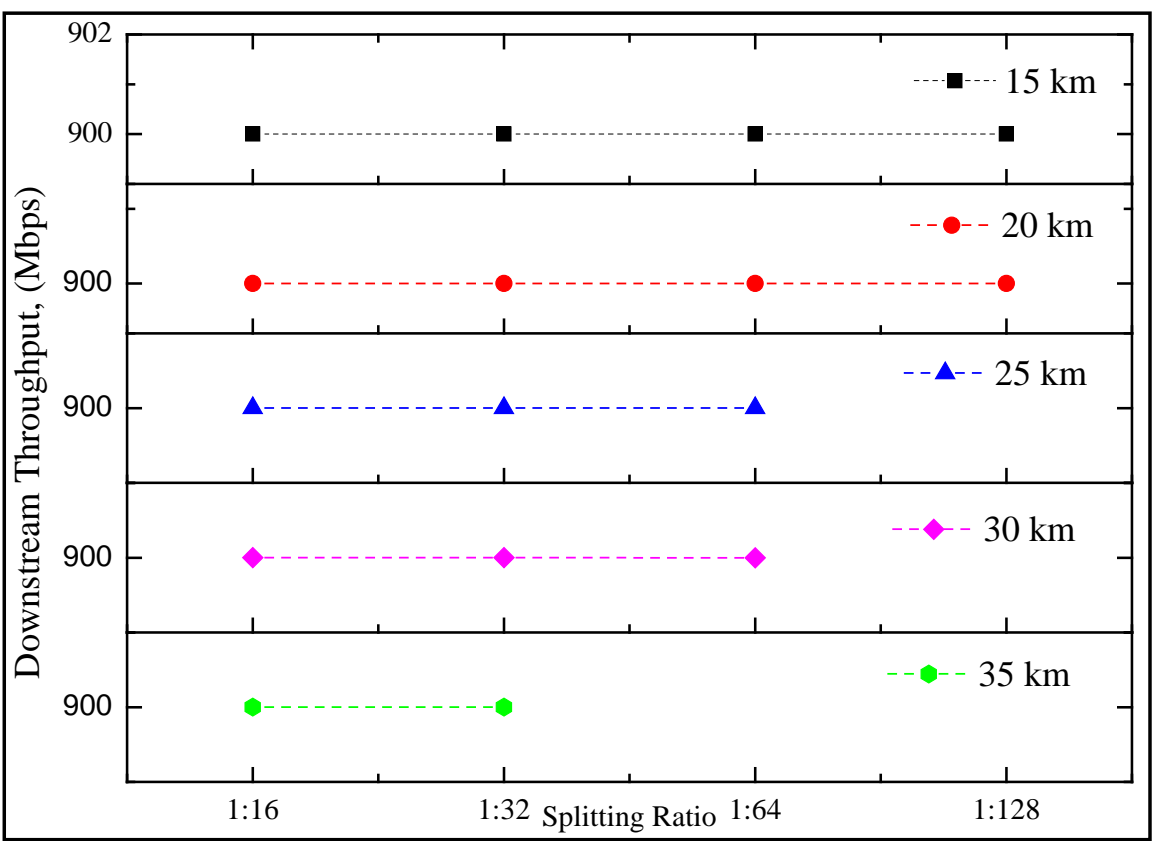

Figure 6. Throughput performance against splitting ratio for downstream transmission.

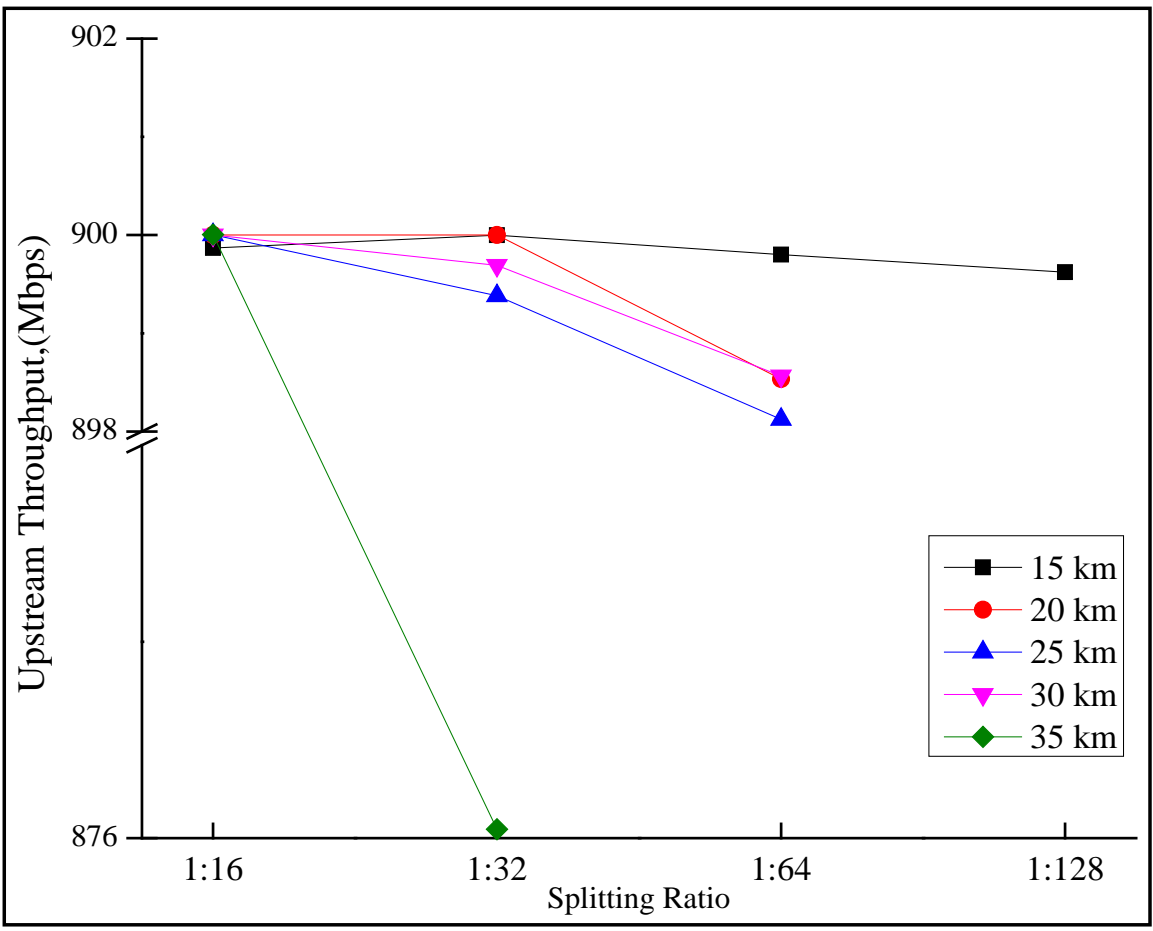

Figure 7. Throughput performance against splitting ratio for upstream transmission.

Mbps. For all distances with splitting ratio of 1:16, the best value of network throughput (900 Mbps) was achieved. However, it can be seen the dropped of upstream throughput when the number of splitting ratio and distance increased. As mentioned earlier, the attenuation contributed by splitting ratio and distance which was affected the signal transmitted from ONU to OLT, and therefore the 
results are explained.

\section{Conclusion}

We demonstrated the performance of XGS-PON system performance over Active Co-existence (ACEX). From the result, the downstream throughput achieved $100 \%$ regardless distance and splitting ratio. For the upstream performance, the throughput showed $97 \%$ up to $35 \mathrm{~km}$ distance with the maximum splitting ratio at 32. In addition, with an optimal performance of ACEX, in terms of NF and gain, the throughput obtained $99 \%$ at the distance of $15 \mathrm{~km}$ with the splitting ratio at 128. The results showed that the proposed ACEX could compensate the link loss up to $43 \mathrm{~dB}$. Based on the findings, the system performance is feasible solution for future upgrading of Next Generation PON systems.

\section{Acknowledgements}

The Authors would like to express gratitude to Telekom Malaysia Berhad (TM) in general, and TM Research \& Development for the grant.

\section{References}

[1] Cisco Visual Networking Index (2016) Forecast and Methodology, 2015-2020. http://www.cisco.com/c/en/us/solutions/collateral/service-provider/visual-networki ng-index-vni/complete-white-paper-c11-481360.html

[2] ITU-T.G.984.2 Amd 2. Gigabit-Capable Passive Optical Networks (G-PON): Physical Media Dependent (PMD) Layer Specification. ITU-T Rec. G.984.2 (2003)/Amd.2 (03/2008). https://www.itu.int/rec/T-REC-G.984.2/en

[3] ITU-T.G.987.1. 10 Gigabit-Capable Passive Optical Networks (XG-PON): General Requirements. ITU-T Rec. G.987.1 (03/16). https://www.itu.int/rec/T-REC-G.987.1/en

[4] Taguchi, K., Asaka, K., Fujiwara, M., Kaneko, S., Yoshida, T., Fujita, Y., Iwamura, H., Kashima, M., Furusawa, S., Sarashina, M., Tamai, H., Suzuki, A., Mukojima, T., Kimura, S., Suzuki, K.-I. and Otaka, A. (2016) Field Trial of Long-Reach and HighSplitting $\lambda$-Tunable TWDM-PON. J. Lightwave Technol, 34, 213-221. https://doi.org/10.1109/JLT.2015.2494606

[5] ITU-T G.9807.1 (2016) 10 Gigabit-Capable Symmetric Passive Optical Network. ITU-T G.9807. https://www.itu.int/rec/T-REC-G.9807.1/en

[6] Huawei Technologies (2010) Next-Generation PON Evolution. www.huawei.com/ilink/en/download/HW_077443

[7] Le Guyader, B., et al. (2012) Dual Reach Extender Based on Optical Amplification for G-PON and Symmetrical 10G-PON Systems. OFC/NFOEC, Los Angeles, 1-3. https://doi.org/10.1364/NFOEC.2012.NTu1J.2

[8] KwangOk, K. and HwanSeok, C. (2016) Real-Time Demonstration of Extended 10G-EPON Capable of 128-Way Split on a $100 \mathrm{~km}$ Distance Using OEO-Based PON Extender. 2016 International Conference on Information and Communication Technology Convergence (ICTC), Jeju Island, 930-932. https://doi.org/10.1109/ICTC.2016.7763333

[9] Dalla Santa, M., Antony, C., Talli, G., Krestnikov, I. and Townsend, P.D. (2016) 
Burst-Mode Analysis of XGPON Raman Reach Extender Employing Quantum-Dot Lasers. Electronics Letters, 52, 1157-1158.

[10] Nesset, D., et al. (2008) Field Experiment with a Hardened GPON Reach Extender with Dual Parenting Protection. Proc. ECOC, Th.2.F.3.

https://doi.org/10.1109/ECOC.2008.4729418

Submit or recommend next manuscript to SCIRP and we will provide best service for you:

Accepting pre-submission inquiries through Email, Facebook, LinkedIn, Twitter, etc. A wide selection of journals (inclusive of 9 subjects, more than 200 journals)

Providing 24-hour high-quality service

User-friendly online submission system

Fair and swift peer-review system

Efficient typesetting and proofreading procedure

Display of the result of downloads and visits, as well as the number of cited articles Maximum dissemination of your research work

Submit your manuscript at: http://papersubmission.scirp.org/

Or contact opj@scirp.org 